ISSN 0103-8478

\title{
Probióticos na avicultura
}

\author{
Probiotics on poultry production
}

\section{Leandro Nagae Kuritza ${ }^{\mathrm{I}^{*}}$ Patrick Westphal ${ }^{\mathrm{I}}$ Elizabeth Santin $^{\mathrm{I}}$}

\section{- REVISÃO BIBLIOGRÁFICA -}

\section{RESUMO}

Com a proibição do uso de antibióticos como melhoradores de desempenho, aumentaram as pesquisas para desenvolver produtos alternativos que fossem eficientes para melhorar o desempenho zootécnico dos animais de produção e manter a saúde intestinal deles, por meio da redução de patógenos e da imuno modulação do trato gastrointestinal. O uso de probióticos já é conhecido há muito tempo, entretanto os mecanismos de ação destes produtos e a interação deles com o organismo animal hospedeiro estão sendo mais profundamente pesquisados agora. Sabe-se que os probióticos auxiliam no equilíbrio da microbiota intestinal, podendo, por meio deste efeito, melhorar o desempenho dos animais. Esta atividade se dá pela produção de diferentes metabólitos com ação antimicrobiana e também pela competição por sítios de ligação com bactérias patogênicas na mucosa do trato gastrointestinal ou através de imunomodulação no organismo animal. Devido a todas as ações dos probióticos, eles são utilizados como melhoradores de desempenho animal e também podem ser uma ferramenta para controle de enterobactérias de importância em saúde pública.

Palavras-chave: imunidade, Salmonella spp., Desempenho Zootécnico, Lactobacillus spp., Bacillus spp., Enterococcus spp.

\section{ABSTRACT}

As antibiotics growth promoters have been banned from animal feed, probiotics have received special attention as alternative products to enhance performance from livestock and keep their gastrointestinal health. Probiotics benefits are known since long time ago, however, the mechanisms of action of these products are being better researched now. Is known that probiotics could balance intestinal microbiot and due to this, they can improve animal performance. This activity is due to the production of different metabolites with antimicrobial activity and competition by bind sites on gastrointestinal mucosal. Due to all this probiotic actions, they are recommended as animal growth promoters and also may be an important tool to control enterobacterias considered risky to public health.

Key words: immunity, Salmonella spp., performance, Lactobacillus spp., Bacillus spp., Enterococcus spp.

\section{INTRODUÇÃO}

Por muito tempo, os antibióticos foram amplamente utilizados na produção animal, seja como forma de tratamento, seja como melhorador de desempenho para favorecer o desenvolvimento dos animais, melhorando seu desempenho zootécnico, visando níveis mais altos de produtividade. Ele atua principalmente sobre a microbiota intestinal, favorecendo o seu equilíbrio. Com isso, há a redução da competição por nutrientes entre a microbiota e o animal e a redução da atividade de patógenos (ANDERSON et al., 1999). Entretanto, o uso dos antibióticos como melhoradores de desempenho levou à preocupação com a seleção de bactérias patogênicas que se tornassem resistentes aos antibióticos usados na terapia humana. Assim, em 2006, diversas moléculas antibióticas tiveram seu uso proibido na União Europeia (EC REGULATION n. 1831/2003).

Após a retirada dos melhoradores de desempenho, foram observados alguns efeitos negativos na produção. Foi verificado aumento no uso de antibióticos da linha humana como terapêuticos, que também podem acarretar o surgimento de bactérias patogênicas resistentes (CASEWELL et al., 2003;

IDepartamento de Medicina Veterinária, Setor de Ciências Agrárias, Universidade Federal do Paraná (UFPR), 80035-050, Curitiba, PR, Brasil. E-mail: leandronkmv@gmail.com.*Autor para correspondência. 
ÁLVAREZ-FERNÁNDEZ et al., 2012; DIARRA et al., 2014). Também foi observada uma síndromeidentificada como Dysbacteriosis, na qual houve aumento no índice de cama molhada, crescimento exagerado da flora intestinal, má absorção, paredes intestinais delgadas e abauladas e queda no desempenho (HUYGHEBAERT et al., 2011).

Segundo CASTANON (2007), os mercados exportadores tiveram de se adaptar à legislação da União Europeia para continuar exportando para estes países. O Brasil, como maior exportador de carne de frango do mundo (UBA, 2013) e tendo a União Europeia como importante mercado (em 2012 foi o destino de $8,2 \%$ das exportações brasileiras), também teve de se adaptar a essas medidas.

Tendo em vista a necessidade da melhoria da produção, juntamente com a preocupação com quadros de toxi-infecção causados por bactérias patogênicas, especialmente as do gênero Salmonella spp., houve a intensificação na busca de produtos alternativos capazes de proporcionar melhor desempenho para os animais, diminuir a contaminação das aves e das carcaças por bactérias patogênicas, sem deixar resíduos nocivos que possam causar problemas de saúde aos consumidores finais da carne de frango. Como exemplo de melhoradores de desempenho alternativos, cita-se enzimas, extratos de plantas, óleos, ácidos orgânicos, prebióticos, probióticos e suas associações (HUYGHEBAERT et al., 2011).

A utilização de probióticos em humanos data do final do século 19 e início do século 20 (FULLER, 1991). Em animais, na união europeia, seu uso foi regulamentado a partir da década de 70 (ANADÓN et al., 2006) e, embora já tenham sido testados desde a década de 70 , foi a restrição do uso de antibióticos que estimulou o crescimento das pesquisas.

Frente a isso, o objetivo desta revisão é abordar a interação dos probióticos com a microbiota intestinal, sua relação com a resposta imunológica e sua capacidade de controlar infecções causadas por bactérias do gênero Salmonella spp.

\section{DESENVOLVIMENTO}

\section{Probióticos}

O termo probióticos foi usado pela primeira vez por LILLY\& STILLWELL (1965) para descrever substâncias produzidas por protozoários que estimulavam o crescimento de outros microorganismos. A partir desse momento, diversos trabalhos foram desenvolvidos objetivando verificar esta ação probiótica. Posteriormente, FULLER (1989) definiu os probióticos como suplementos compostos de microorganismos vivos que beneficiam a saúde do hospedeiro por meio do equilíbrio da microbiota intestinal. Mais tarde, HAVENAAR et al. (1992), complementando a definição de FULLER (1989), definiram os probióticos como uma única ou mistura de culturas de microrganismos vivos que, quando aplicado a animais ou em seres humanos, afetam beneficamente o hospedeiro, melhorando as propriedades da microbiota endógena. Estas duas definições (FULLER, 1989; HAVENAAR et al., 1992) são aceitas e mais comumente utilizadas pela comunidade científica.

Os probióticos podem ser definidos como espécies colonizadoras, como o Lactobacillus e Enterococcus spp. ou não colonizadoras, de trânsito intestinal livre, como o Bacillus spp. e o Saccharomyces cerevisiae (HUYGHEBAERT et al., 2011).

Segundo SALMINEN et al. (1996), existem alguns requerimentos para definir uma bactéria como um probiótico efetivo: a habilidade de aderir às células do hospedeiro; excluir ou reduzir a aderência de bactérias patogênicas; persistir e se multiplicar; produzir ácidos, peróxido de hidrogênio e bacterocinas que impeçam o crescimento de bactérias patogênicas; ser seguro; não invasivo; não carcinogênico e não patogênico e possuir a capacidade de se agregar as outras bactérias, para formar uma microbiota balanceada.

Embora existam diversas espécies de bactérias que possam apresentar características probióticas, apenas as cepas ácido-láticas são consideradas importantes com relação à nutrição e à alimentação (HOLZAPFEL et al., 2001). A descrição geral das bactérias incluídas neste grupo é que são Gram-positivas, não esporulantes, cocos ou bastonetes "não respirantes", que produzem ácido láctico como principal produto final durante a fermentação de carboidratos (AXELSSON, 2005).

$\mathrm{O}$ mecanismo de ação dos probióticos não está bem esclarecido ainda. Presume-se que são diversos processos que levam ao equilíbrio da microbiota intestinal, e que proporcionam os demais efeitos desejáveis. Segundo LEE et al. (2010), os probióticos fornecidos diretamente na ração melhoram a saúde e a produtividade das aves através do equilíbrio da microflora intestinal e da modulação do sistema imunológico. Alguns dos métodos pelos quais os probióticos controlam a microbiota são a produção de substâncias antimicrobianas, a competição por sítios de ligação e o estímulo ao sistema imunológico.

Nos animais, os probióticos são usados para fins diferentes do que para seres humanos. A principal função do uso dos probióticos na produção animal 
é a obtenção de melhores índices de desempenho zootécnico (Tabela 1), visando a melhores índices de produtividade com menores gastos. A melhora de desempenho zootécnico pode estar associada à redução da contaminação por Salmonella sp. (VILÀ et al., 2009) e à melhora da imunidade do animal (KHAKSEFIDI e GHOORCHI, 2006). O contato com o ambiente logo após o nascimento favorece o desenvolvimento mais rápido da microbiota. Esta, formada logo após a eclosão, interage com o trato digestório e com o sistema imunológico dos animais, podendo afetá-los de forma positiva ou negativa. A colonização de diferentes porções do trato gastrointestinal por bactérias específicas, como Lactobacillus, Streptococcus, entre outras, pode ocorrer pela associação com a camada de muco ou pela adesão à superfície e células epiteliais. Esta adesão atua como a primeira barreira de defesa contra os microorganismos nocivos e contra toxinas (NOUSIAINEN et al., 2005).

Os probióticos devem ser usados para corrigir disfunções locais do sistema imunológico, estabilizar a função da barreira mucosa do intestino, para impedir a fixação de microorganismos patogênicos e influenciar o metabolismo intestinal (HOLZAPFEL et al., 1998). Na tabela 2, estão listados os microorganismos considerados como probióticos, de acordo com HOLZAPFEL et al. (1998).

$\mathrm{Na}$ União Europeia, as principais espécies utilizadas como probióticos pertencem aos gêneros

Tabela 1 - Probióticos que favorecem o desempenho zootécnico dos animais.

\begin{tabular}{|c|c|c|c|}
\hline Probiótico & Dosagem & Efeito & Autor \\
\hline Pediococcus acidilactici & $1 \mathrm{~g} \mathrm{~kg}^{-1}$ & $\begin{array}{l}\text { - Aumento do peso corporal a partir da } \\
\text { segunda semana; } \\
\text { - Aumento do Ganho de peso (GP) a } \\
\text { partir da segunda semana; } \\
\text { - Redução do colesterol na quarta e } \\
\text { sexta semanas. }\end{array}$ & ALKHALF et al., 2010 \\
\hline B. subtilis + S. cerevisae & $\begin{array}{l}10^{6} \text { B. subtilis e } 10^{8} \mathrm{~S} . \\
\text { cerevisae }\end{array}$ & $\begin{array}{l}\text { - Aumento do GP; } \\
\text { - Aumento do consumo de ração. }\end{array}$ & CHEN et al., 2009 \\
\hline B. cereus var. toyoi & $\begin{array}{l}10^{10} / \mathrm{g} \text { B. cereus NCIMB } \\
40112 / \mathrm{CNCM} \mathrm{I}-1012\end{array}$ & $\begin{array}{l}\text { - Aumento do GP diário médio em } 3,4 \mathrm{~g} \text {; } \\
\text { - Aumento do peso corporal em } 141 \mathrm{~g} \text {; } \\
\text { - Redução do número de aves positivas } \\
\text { para } S \text {. Enteritidis. }\end{array}$ & VILÁ et al., 2009 \\
\hline B. subtilis & $50 \mathrm{mgkg}^{-1}$ & $\begin{array}{l}\text { - Aumento do GP; } \\
\text { - Melhora da conversão alimentar } \\
\text { (C.A.); } \\
\text { - Aumento da resposta de Anticorpos } \\
\text { (Ac) contra soro de cordeiro; } \\
\text { - Aumento de Ac contra o vírus da } \\
\text { doença de Newcastle. }\end{array}$ & KLAKSEFIDI et al., 2006 \\
\hline $\begin{array}{l}\text { L. plantarum, L. bulgaricus, L. } \\
\text { acidophilus, L. rhamnosus, B. } \\
\text { bifidum, S. thermophilus, E. } \\
\text { faecium, A. oryzae e C. } \\
\text { pintolopessi }\end{array}$ & 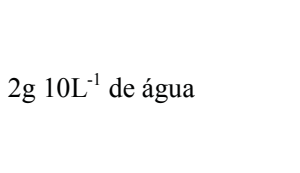 & $\begin{array}{l}\text { - aumento do peso corporal na } 2^{-}, 4^{-a}, 5^{-a} \\
\text { e } 6^{-} \text {semanas. }\end{array}$ & KABIR et al., 2004 \\
\hline B. subtilis & $1 \times 10^{10}$ UFC $^{-1}$ & $\begin{array}{l}\text { - Aumento do peso corporal; } \\
\text { - Melhor CA de } 21 \text { a } 42 \text { dias. }\end{array}$ & FRITTS et al., 2000 \\
\hline $\begin{array}{l}12 \text { cepas de Lactobacillus de } 4 \\
\text { espécies (L. acidophilus, L. } \\
\text { fermentum, L. crispatus e L. } \\
\text { brevis) }\end{array}$ & $\begin{array}{l}0,10 \% \text { da cultura de } \\
\text { Lactobacillus }\end{array}$ & $\begin{array}{l}\text { - Aumento do peso corporal aos } 21 \text { e } 42 \\
\text { dias; } \\
\text { - Melhor CA de } 1 \text { a } 21,21 \text { a } 42 \text { e } 1 \text { a } 42 \\
\text { dias. }\end{array}$ & JIN et al, 1998 \\
\hline
\end{tabular}

Ciência Rural, v.44, n.8, ago, 2014. 
Tabela 2 - Microorganismos considerados como probióticos.

\begin{tabular}{|c|c|c|c|}
\hline Lactobacillus & Bifidobacterium & $\begin{array}{l}\text { Outras bactérias produtoras de } \\
\text { ácido lático }\end{array}$ & Não produtoras de ácido lático \\
\hline L. acidophilus & B. adolescentis & Enterococcus faecalis $^{2}$ & Bacillus cereus var. toyoi ${ }^{2,3}$ \\
\hline L. amylovorus ${ }^{1}$ & B. animalis & Enterococcus faecium & Escherichia coli strainnissle \\
\hline L. casei & B. bifidum & Lactococcus lactis $^{4}$ & Propionibacterium freudenreichii ${ }^{2,3}$ \\
\hline L. crispatus & B. breve & Leuconstocmesenteroides & Saccharomyces cerevisiae $^{3}$ \\
\hline L. delbrueckii subsp. Bulgaricus ${ }^{4}$ & B. infantis & Pediococcus acidilactici ${ }^{4}$ & Saccharomyces boulardiii, \\
\hline L. gallinarum ${ }^{2}$ & B. lactis $^{5}$ & Sporolactobacillus inulinus ${ }^{2}$ & \\
\hline L. gasseri & B. longum & Streptococcus thermophilus ${ }^{4}$ & \\
\hline \multicolumn{4}{|l|}{ L. johnsonii } \\
\hline \multicolumn{4}{|l|}{ L. paracasei } \\
\hline \multicolumn{4}{|l|}{ L. plantarum } \\
\hline \multicolumn{4}{|l|}{ L. reuteri } \\
\hline L. rhamnosus & & & \\
\hline
\end{tabular}

Adaptado de HOLZAPFEl et al. (1998)

${ }^{1}$ HOLZAPFEL et al. (2002).

${ }^{2}$ Usado principalmente em animais

${ }^{3}$ Usado principalmente em preparações farmacêuticas.

${ }^{4}$ Pouco se sabe sobre as propriedades probióticas.

${ }^{5}$ Provavelmente, igual ao B. animalis.

Bacillus (B. cereus var. toyoi, B. licheniformis, B. subtilis), Enterococcus (E. faecium), Lactobacillus (L. acidophilus, L. casei, $L$. farciminis, $L$. plantarum, L. rhamnosus), Pediococcus (P. acidilactici) e Streptococcus (S. infantarius). Outrosprobióticos pertencem ao grupo das leveduras, como Saccharomyces cerevisiae e Kluyveromyces (ANADÓN et al., 2006). No Brasil, as espécies de probióticos mais utilizadas na avicultura são similares às utilizadas na União Europeia (FARIA FILHO et al., 2006).

Forma de ação dos probióticos

A principal forma de ação descrita para os probióticos se dá pela produção de alguns metabólitos que irão atuar como inibidores do crescimento de outras bactérias, especialmente as patogênicas. Os metabólitos produzidos podem ser ácidos, principalmente o lático e o acético, dióxido de carbono, peróxido de hidrogênio, bacterocinas e peptidios antimicrobianos. Além disso, os probióticos se aderem mais facilmente à mucosa do hospedeiro, impedindo a adesão e desenvolvimento de bactérias patogênicas. Em um estudo realizado por TODORIKI et al. (2001), duas cepas diferentes de Lactobacillus (L. reuteri e L. crispatus)foram capazes de inibir a adesão de Escherichia coli enterotoxigênica, Salmonella Typhimurium e Enterococcus faecalis. Esta capacidade foi testada in vitro em células Caco-2, em que a adesão e a produção de bacterocinas pelas bactérias probióticas inibiu a adesão de bactérias patogênicas.
Por meio da fermentação de hexoses, algumas bactérias, especialmente as consideradas como probióticos, possuem a capacidade de produzir ácido lático, por homofermentação e ácido lático, acético/ etanol e dióxido de carbono por heterofermentação (OUWEHAND \& VESTERLUND, 2005). Esses ácidos apresentam ação contra bactérias, fungos e leveduras. Sua ação vai depender do $\mathrm{pH}$ do ambiente e da capacidade de dissociação dos ácidos formados, proporcionando maior ou menor efetividade.

Bactérias produtoras de ácido lático, em presença de oxigênio, são capazes de produzir peróxido de hidrogênio, que também atua inibindo o crescimento de bactérias. ITO et al. (2003) conseguiram estimular a produção de peróxido de hidrogênio por algumas cepas de Lactobacillus lactis subsp. lactis. Uma destas cepas foi testada contra Enterococcus faecalis, Enterococcus faecium, Escherichia coli Enterotoxigênica, Listeriaivanovii, Staphylococcus aureus, Yersinia enterocolitica e Aeromonas hydrophila e foi eficaz na redução da contagem destas bactérias.

Com relação à produção de dióxido de carbono, este pode gerar anaerobiose ou agir diretamente sobre as bactérias (LINDGREN \& DOBROGOSZ, 1990), nos dois casos inibindo o crescimento delas.

Apesar de se conhecer que alguns probióticos são capazes de produzir compostos antimicrobianos, nem sempre é conhecida a natureza dessas substâncias antimicrobianas. NAZEF et al. (2008) demonstraram que o Enterococcus faecalis 
apresentou atividade antilisteria e, de forma mais fraca, anticampylobacter. Segundo os autores, o E. Faecalis é capaz de produzir tanto bacterocinas como peptidios antimicrobianos.

\section{Probióticos e imunidade}

Sabe-se que uma das características dos probióticos é o estimulo do sistema imunológico. Os probióticos podem atuar tanto modulando a resposta imune inata como a adquirida, favorecendo o combate aos microorganismos (FLEIGE et al., 2009). Segundo LEE et al. (2010), os probióticos fornecidos na ração são capazes de modular a resposta humoral e celular para aumentar a proteção através do sistema imunológico. Entretanto, não se sabe precisamente como ocorre essa interação.
Os estímulos produzidos pela colonização dos probióticos são essenciais para o desenvolvimento de um sistema imunológico funcional e balanceado, incluindo a presença de linfócitos $\mathrm{T}$ e $\mathrm{B}$ na lâmina própria, assim como a expansão e maturação de $\operatorname{IgA}$ e também na indução de tolerância por parte dos antígenos presentes (BORCHERS et al., 2009). O uso dos probióticos favorece a resposta contra algumas vacinas, aumenta as imunoglobulinas tanto no sangue como na mucosa e estimula a maturação de linfócitos $\mathrm{T}$ e B (HAGHIGHI et al. 2006) (Tabela 3). Os resultados demonstrados na tabela 3 ilustram os diferentes efeitos dos probióticos sobre a imunidade dos animais.

Outro dado interessante é a grande variedade de probióticos que podem ser utilizados para estimular tanto a imunidade inata como a imunidade adquirida

Tabela 3 - Efeitos dos probióticos sobre o sistema imunológico dos animais.

\begin{tabular}{|c|c|c|c|}
\hline Probiótico & Desafio & Efeito & Autor \\
\hline $\begin{array}{l}\text { Lactobacillus } \quad \text { sp. }+\underset{\text { B. }}{\text { cereus }+} \quad \text { Astragalus } \\
\text { polyssacaride } \\
\text { (preb) })^{1}\end{array}$ & $\begin{array}{l}\text { Vacina contra o virus da doença } \\
\text { de Newcastle (NDV) }\end{array}$ & $\begin{array}{l}\text { - Aumento de Ac contra NDV; } \\
\text { - Aumento de linfócito T } \\
\text { - Aumento de Lactobacillus e } \\
\text { Bifdobacterium }\end{array}$ & Li et al., 2009 \\
\hline B. subtilis ${ }^{1}$ & $\begin{array}{l}\text { Glóbulos vermelhos de ovinos e } \\
\text { vacina contra NVD }\end{array}$ & $\begin{array}{l}\text { - Aumento de Ac contra glóbulos } \\
\text { vermelhos de cordeiro; } \\
\text { - Aumento de Ac contra NDV. }\end{array}$ & KHAKSEFIDI et al., 2006 \\
\hline Lactobacillus sp. ${ }^{1}$ & Eimeria acervulina & $\begin{array}{l}\text { - Aumento de CD3, CD4, CD8 e } \\
\text { BTCR } \\
\text { - Diminuição da excreção de oocistos. }\end{array}$ & DALLOU et al., 2003 \\
\hline $\begin{array}{l}\text { L. reuteri, L. salivarius, } L \text {. } \\
\text { acidophilus e Flora cecal }{ }^{1}\end{array}$ & Salmonella Enteritidis & $\begin{array}{l}\text { - Aumento de CD3, CD4 e CD8 no } \\
\text { trato gastrointestinal. }\end{array}$ & NOUJAIM et al., 2008 \\
\hline $\begin{array}{l}\text { L. acidophylus, B. bifidum, } \\
\text { Streptococcus faecalis }{ }^{1}\end{array}$ & $\begin{array}{l}\text { Toxoide tetânico, } \alpha \text { toxina do } \boldsymbol{C} \text {. } \\
\text { perfringens e Albumina bovina }\end{array}$ & $\begin{array}{l}\text { - Aumento de IgA, IgG e IgM contra } \\
\text { os desafios. }\end{array}$ & HAGHIGHI, 2006 \\
\hline B.subtilis (varias cepas) ${ }^{1}$ & Sem desafio & $\begin{array}{l}\text { - Aumento de óxido nítrico; } \\
\text { - Aumento da fagocitose pelos } \\
\text { macrófagos. }\end{array}$ & LEE et al., 2011 \\
\hline Enterococcus faecium $^{2}$ & Vacina contra cinomose & $\begin{array}{l}\text { - Aumento de IgA fecal; } \\
\text { - Aumento de IgA e IgG contra } \\
\text { cinomose; } \\
\text { - Aumento de células B maduras. }\end{array}$ & BENYACOUB et al., 2003 \\
\hline Enterococcus faecium $^{3}$ & Giardia intestinalis & $\begin{array}{l}\text { - Aumento de IgA contra Giárdia; } \\
\text { - Aumento de IgG contra Giárida no } \\
\text { soro; } \\
\text { - Aumento de CD4 no soro; } \\
\text { - Diminuição da presença de giárdia. }\end{array}$ & BENYACOUB et al., 2005 \\
\hline Enterococcus faecium $^{4}$ & Sem desafio & $\begin{array}{l}\text { - Diminuição de CD8 na mucosa } \\
\text { jejunal; } \\
\text { - Diminuição de E. coli no intestino. }\end{array}$ & SCHAREK et al., 2005 \\
\hline
\end{tabular}

1 - Avaliação em frango de corte.

2 - Avaliação em cães.

3 - Avaliação em animais de laboratório.

4 - Avaliação em suínos

Ciência Rural, v.44, n.8, ago, 2014. 
dos animais. O fornecimento de Bacillus subtilis como probiótico foi capaz de estimular a atividade de macrófagos através do aumento da produção de óxido nítrico e de sua atividade fagocítica (LEE et al., 2011). Este aumento proporciona ao animal resposta mais rápida frente a qualquer microorganismo desconhecido que passe pelo trato gastrintestinal. Essa característica se torna cada vez mais interessante, pois favorece a saúde do trato gastrintestinal.

A presença de bactérias comensais na microbiota é essencial para a produção de $\operatorname{IgA}$ intestinal em alguns animais, pois ela não é encontrada em animais livres de patógenos e a colonização do trato gastrintestinal por estas bactérias estimula o desenvolvimento dessa imunoglobulina (BOS et al., 2001). Alguns autores (Tabela 3) demonstraram o aumento na produção de IgA no trato gastrintestinal e no soro, facilitando o combate a patógenos presentes no trato gastrintestinal. Esta ação sugere que probióticos podem atuar como adjuvantes, realizando estímulo prévio do sistema imunológico, acelerando a resposta específica dos animais.

No trabalho realizado por SCHAREK et al. (2005), o Enterococcus faecium foi capaz de reduzir a contagem de linfócitos T CD8+ (linfócitos $\mathrm{T}$ citotóxicos que induzem à apoptose a célula infectada, ERF, 2004) na mucosa do jejuno, e os autores sugerem que isso ocorra devido à redução da presença de patógenos na mucosa, por meio de mecanismos de exclusão competitiva.

Ação dos probióticos sobre a Salmonella spp

As infecções por Salmonella spp. são muito preocupantes na avicultura. As aves são consideradas os maiores reservatórios dessa bactéria, e, segundo MORSE \& DUNCAN (1974), podem ser fonte de infecção para outros animais e para seres humanos. O maior problema desta transmissão ocorre quando as infecções são por Salmonella paratíficas, que geralmente não apresentam sinais clínicos aparentes nas aves (HOFER et al., 1997) e são as mais nocivas, quando se trata de saúde pública.

Como os probióticos podem atuar inibindo o desenvolvimento de bactérias patogênicas no trato gastrintestinal dos animais, mais especificamente contra bactérias do gênero Salmonella spp., menores serão as chances de ocorrer contaminação das carcaças por rompimento de vísceras no interior do abatedouro (RASSCHAERT et al., 2007). Diversos autores estão listados na tabela 4 , os quais vêm pesquisando a importância dos probióticos como inibidores do crescimento de Salmonella spp.. O

Tabela 4 - Ação dos probióticos sobre Salmonella spp.

\begin{tabular}{|c|c|c|c|}
\hline Probiótico & Desafio & Efeito & Autor \\
\hline Bacillus cereus var Toyoi & $10^{4}$ Salmonella Enteritidis & $\begin{array}{l}\text { - Aumento do ganho de peso e conversão; } \\
\text { - Redução de } 100 \% \text { na presença de SE. }\end{array}$ & VILÀ et al., 2009 \\
\hline $\begin{array}{l}\text { Lactobacillus } \quad \text { spp. } \\
\text { espécies })\end{array}$ & $10^{4}$ Salmonella Enteritidis & $\begin{array}{l}\text { - Redução da recuperação de SE } 24 \text { horas } \\
\text { pós tratamento; } \\
\text { - Redução da presença de SE em } \\
\text { tratamento via cloacal. }\end{array}$ & HIGGINS et al., 2008 \\
\hline Lactobacillus casei & $10^{8}$ Salmonella Typhimurium & $\begin{array}{l}\text { - Redução da contagem de ST em baço, } \\
\text { intestino e fígado; } \\
\text { - Redução na infiltração de neutrófilos; } \\
\text { - Aumento da atividade fagocítica de } \\
\text { macrófagos; } \\
\text { - Aumento de IgA no intestino. }\end{array}$ & LEBLANC et al., 2010 \\
\hline L. rhamnosus e L. reuteri & Salmonella Thphimurium & $\begin{array}{l}\text { - Redução de } 99 \% \text { da viabilidade de } \mathrm{ST} \\
\text { em pH } 4,5 \text { e microaerobiose; } \\
\text { - Redução de } 20 \% \text { de ST em pH7,5 e } \\
\text { microaerobiose. }\end{array}$ & MARIANELLI et al., 2010 \\
\hline $\begin{array}{l}\text { - L. casei, L. delbrueckii, } \mathbf{L} \text {. } \\
\text { fermentum; } \\
\text { - Lactobacillus spp. }(11 \\
\text { espécies) }\end{array}$ & $10^{4}$ Salmonella Enteritidis & $\begin{array}{l}\text { - Redução de SE em aves tratadas por } 24 \\
\text { horas, uma hora pós-inoculação; } \\
\text { - Redução de SE em aves tratadas } 24 \\
\text { horas pré-inoculação. }\end{array}$ & HIGGINS et al., 2010 \\
\hline $\begin{array}{l}\text { Aviguard }{ }^{\circledR} \text {, Saccharomyces } \\
\text { cereviseae e Pediococcus } \\
\text { acidilactici }\end{array}$ & $\begin{array}{l}\text { Salmonella spp. Proveniente } \\
\text { do incubatório }\end{array}$ & $\begin{array}{l}\text { - Redução da contaminação no corpo da } \\
\text { ave, na carcaça e no ceco. }\end{array}$ & Al-Zenki et al., 2009 \\
\hline
\end{tabular}

Ciência Rural, v.44, n.8, ago, 2014. 
trabalho realizado por AL-ZENKI et al. (2009) comprova a capacidade da redução da contaminação de carcaças em abatedouro por diminuir a presença de Salmonella spp. no trato gastrointestinal das aves. Esta redução é de extrema importância, tendo em vista que a salmonelose é a principal fonte de toxiinfecções alimentares para seres humanos.

\section{CONCLUSÃO}

O uso de probióticos como melhoradores de desempenho é recomendado devido à capacidade destesem melhorar o desempenho zootécnico dos animais, seja por meio da redução da contaminação microbiana, ou pela modulação da resposta imunológica dos animais. Entretanto, existem alguns pontos não muito bem elucidados na ação dos probióticos como a natureza de bacterocinas e outras substâncias com função antimicrobiana e também o modo de ação como imunomodulador no organismo animal. Esta lacuna no conhecimento leva à necessidade de mais pesquisas.

\section{REFERÊNCIAS}

AL-ZENKI, S. F. et al. Effects of using a chicken-origin competitive exclusion culture and probiotic cultures on reducing Salmonella in broilers. Journal of Applied Poultry Research, v.18, p.23-29, 2009. Disponível em: <http://japr.oxfordjournals. org/content/18/1/23.full.pdf + html $>$. Acesso em: 18 out. 2011.

ALKHALF, A. et al. Influence of probiotic supplementation on blood parameters and growth performance in broiler chickens. Saudi Journal of Biological Sciences, v.17, p.219-225, 2010. Disponível em: <http://www.sciencedirect.com/science/article/pii/ S1319562X10000434>. Acesso em: 17 mar. 2013.

ÁLVAREZ-FERNANDEZ, E. et al. Prevalence and antimicrobial resistance of Salmonella serotypes isolated from poultry in Spain Comparison between 1993 and 2006. International Journal of Food Microbiology, v.153, n.3, p.281-287, 2012. doi. <http:// dx.doi.org/10.1016/j.ijfoodmicro.2011.11.011>

ANADÓN, A. et al. Probiotics for animal nutrition in the European Union. Regulation and safety assessment. Regulatory Toxicology and Pharmacology, v.45, p. 91-95, 2006. Disponível em: <http:// www.sciencedirect.com/science/article/pii/S0273230006000298>. Acesso em: 19 mar. 2013.

ANDERSON, D.B. et al. Gut microbiology and growth-promoting antibiotics in swine. Pig News and Information, v.20, p $115 \mathrm{~N}-122 \mathrm{~N}, 1999$

AXELSSON, L. Lactic acid bacteria: classification and physiology. In: SALMINEN, S. et al. Lactic acid bacteria microbiological and functional aspects. New York: Marcel Dekker, 2005. Cap.1.

BENYACOUB, J. et al. Supplementation of Food with Enterococcus faecium (SF68) stimulates immune functions in young dogs. Journal of Nutrition, v.133, n.4, p.1158-1162, 2003.
Disponível em: <http://jn.nutrition.org/content/133/4/1158.long>. Acesso em: 19 mar. 2013

BENYACOUB, J. et al. Enterococcus faecium SF68 enhances the immune response to Giardia intestinalis in mice. Journal of Nutrition, v.135, n.5, p.1171-1176, 2005. Disponível em: <http://jn.nutrition.org/ content/135/5/1171.long>. Acesso em: 19 mar. 2013.

BORCHERS, A.T. et al. Probiotics and immunity. Journal of Gastroenterolology, v.44, p.26-46, 2009. Disponível em: <http:// www.springerlink.com/content/3656030247656066/fulltext.pdf $>$. Acesso em: 25 out. 2011. doi: 10.1007/s00535-008-2296-0.

BOS, N.A. et al. T cell control of the gut IgA response against commensal bacteria. Gut, v.48, p.762-764, 2001. Disponível em: $<$ http://gut.bmj.com/content/48/6/762.full.pdf + html $>$. Acesso em: 20 out. 2011

CASEWELL, M. et al. The European ban on growth-promoting antibiotics and emerging consequences for human and animal health. Journal of Antimicrobial Chemotherapy, v.52, p. 159-161, 2003.

CASTANON, J.I.R. History of the use of antibiotic as growth promoters in european poultry feeds. Poultry Science, v.86, p.2466-2471, 2007. Disponível em: <http://ps.oxfordjournals.org/ content/86/11/2466.full.pdf + html $>$. Acesso em: 22 out. 2011.

CHEN, K.L. et al. Effects of Bacillus subtilis var. natto and Saccharomyces cerevisiae mixed fermented feed on the enhanced growth performance of broilers. Poultry Science, v.88, p.309315, 2009. Disponível em: <http://ps.oxfordjournals.org/ content/88/2/309.full.pdf + html $>$. Acesso em 10 nov. 2011

DALLOUL, R.A. et al. Enhanced mucosal immunity against Eimeria acervulina in broilers fed a Lactobacillus-based probiotic. Poultry Science, v.82, p.62-66, 2003. Disponível em: <http:// ps.oxfordjournals.org/content/82/1/62.full.pdf + html $>$. Acesso em: 25 out. 2011.

DIARRA, M.S. et al. Antibiotic resistance and diversity of Salmonella enterica serovars associated with broiler chickens. Journal of Food Protection, v.77, n.1, p. 40-49, 2014. doi: <http:// dx.doi.org/10.4315/0362-028.JFP-13-251>.

ERF, G.F. Cell-mediated immunity in poultry. Poultry Science, v.83, v.4, p.580-590, 2004. Disponível em: $<$ http://ps.oxfordjournals. org/content/83/4/580.full.pdf + html $>$. Acesso em: 16 mar. 2013.

FARIA FILHO, D.E. et al. Probiotics for broiler chickens in brazil: systematic review and meta-analysis. Brazilian Journal of Poultry Science, v.8, n.2, p.89-98, 2006. Disponível em: <http://www.scielo.br/scielo.php?pid=S1516635X2006000200004\&script=sci_arttext $>$. Acesso em: 03 abr. 2013.

FLEIGE, S. et al. The immunomodulatory effect of lactulose on Enterococcus faecium fed preruminant calves. Journal of Animal Science, v.87, p.1731-1738, 2009. Disponível em: $<$ http:// jas.fass.org/content/87/5/1731.full.pdf + html $>$. Acesso em: 29 out. 2011. doi: $10.2527 /$ jas.2007-0494.

FULLER, R. Probiotics in man and animals. Journal of Applied Bacteriology, v.66, p.365-378, 1989. Disponível em: <http:// onlinelibrary.wiley.com/doi/10.1111/j.1365-2672.1989. tb05105.x/pdf $>$. Acesso em: 10 out. 2011. doi: 10.1111/ j. $1365-2672$ 
FULLER, R. Probiotics in human medicine. Gut, v.32, p.439-442, 1991.

HAGHIGHI, H.R. et al. Probiotics stimulate production of natural antibodies in chickens. Clinical and Vaccine Immunology, v.13, n.9, p.975-980, 2006. Disponível em: <http://cvi.asm.org/ content/13/9/975.full.pdf + html $>$. Acesso em: 30 out. 2011

HAVENAAR, R. et al. Selection of strains for probiotic use. In: FULLER, R. Probiotics, the scientific basis. London: Chapman \& Hall, 1992. p.209-224.

HIGGINS, S.E. et al. Evaluation of a Lactobacillus-based probiotic culture for the reduction of Salmonella Enteritidis in neonatal broiler chicks. Poultry Science, v.87, p.27-31, 2008. Disponível em: $\quad<$ http://ps.oxfordjournals.org/content/87/1/27.full.pdf + html $>$. Acesso em: 08 nov. 2011. doi: 10.3382/ps.2007-00210.

HIGGINS, J.P. et al. Effect of lactic acid bacteria probiotic culture treatment timing on Salmonella Enteritidis in neonatal broilers. Poultry Science, v.89, p.243-247, 2010. Disponível em: <http:// ps.oxfordjournals.org/content/89/2/243.full.pdf + html $>$. Acesso em: 12 nov. 2011. doi: 10.3382/ps.2009-00436.

HOFER, E. Prevalência de sorovares de Salmonella isolados de aves no Brasil. Pesquisa Veterinária Brasileira, v.17, n.2, p.55-621997. Disponível em: <http://www.scielo.br/pdf/pvb/ v17n2/0917.pdf $>$. Acesso em: 12 nov. 2011. doi: 10.1590/S0100736 X1997000200003.

HOLZAPFEL, W.H. et al. Overview of gut flora and probiotics. International Journal of Food Microbiology, v.41, p.85-101, 1998. Disponível em: <http://ac.els-cdn.com/ S0168160598000440/1-s2.0-S0168160598000440-main.pdf?_ti $\mathrm{d}=3 \mathrm{f} 5 \mathrm{e} 47 \mathrm{e} 3 \mathrm{c} 87 \mathrm{aa} 17 \mathrm{be} 6 \mathrm{~d} 5 \mathrm{fedf33} \mathrm{c} 1 \mathrm{e} 1 \mathrm{a} 4 \& \mathrm{acdnat}=1334348503$ f137e6b219ac01552e35c24bd0525804>. Acesso em: 12 nov. 2011. doi: 10.1016/S0168-1605(98)00044-0.

HOLZAPFEL, W.H. et al. Taxonomy and important features of probiotic microorganisms in food and nutrition. American Journal of Clinincal Nutrition, v.73, suppl, p.365S-373S, 2001. Disponível em: <http://www.ajcn.org/content/73/2/365S.full. pdf + html $>$. Acesso em: 08 nov. 2011.

HOLZAPFEL, W.H. et al. Introduction to pre- and probiotics. Food Research International, v.35, p.109-116, 2002. Disponível em: <http:/www.sciencedirect.com/science/article/pii/S0963996 901001715>. Acesso em: 12 nov. 2011. doi: 10.1016/S09639969(01)00171-5.

HUYGHEBAERT, G. et al. An update on alternatives to antimicrobial growth promoters for broilers. Veterinary Journal, v.187, p.182-188, 2011. Disponível em: <http://ac.els-cdn.com/ S1090023310000869/1-s2.0-S1090023310000869-main.pdf? ti $\mathrm{d}=\mathrm{f} 053017 \mathrm{c} 1 \mathrm{~d} 1986896048 \mathrm{e} 0 \mathrm{f} 516 \mathrm{fc} 5 \mathrm{a} 57$ \&acdnat $=133434920 \overline{3}$ d9e669233cfdc68234c3121781b7fbb2>. Acesso em: 12 nov. 2011. doi: 10.1016/j.tvj1.2010.03.003.

ITO, A. et al. The Screening of hydrogen peroxide-producing lactic acid bacteria and their application to inactivating psychrotrophic food-borne pathogens. Current Microbiology, v.47, p,231-236, 2003. Disponível em: <http://www.springerlink.com/content/ xw5xkxwc3wuxvvxf/fulltext.pdf>. Acesso em: 12 nov. 2011. doi: 10.1007/s00284-002-3993-1.

JIN, L.Z. et al. Growth performance, intestinal microbial populations, and serum cholesterol of broilers fed diets containing Lactobacillus cultures. Poultry Science, v.77 p.1259-1265, 1998.
Disponível em: <http://ps.oxfordjournals.org/content/77/9/1259. full.pdf+html $>$. Acesso em: 17 mar. 2013.

KABIR, S.M.L. et al. The dynamics of probiotics on growth performance and immune response in broilers. International Journal of Poultry Science, v.3, n.5, p.361-364, 2004. Disponível em: <http:// www.pjbs.org/ijps/fin205.pdf>. Acesso em: 17 mar. 2013.

KHAKSEFIDI, A. et al. Effect of probiotic on performance and immunocompetence in broiler chicks. Journal of Poultry Science, v.43, p.296-300, 2006. Disponível em: <http://www. jstage.jst.go.jp/article/jpsa/43/3/296/_pdf>. Acesso em: 12 nov. 2011. doi: $10.2141 /$ jpsa.43.296.

DE LEBLANC, A. de M. et al. Anti-infective mechanisms induced by a probiotic Lactobacillus strain against Salmonella entericaserovar Typhimurium infection. International Journal of Food Microbiology, v.138, p.223-231, 2010. Disponível em: $<$ www.sciencedirect.com/science/article/pii/S0168160510000371>. Acesso em: 12 nov. 2011. doi: 10.1016/j.ijfoodmicro.2010.01.020.

LEE, K. et al. Direct-fed antimicrobials and their impact on the intestinal microflora and immune system of chickens. Journal of Poultry Science, v.47, p.106-114, 2010. Disponível em: <http:// www.jstage.jst.go.jp/article/jpsa/47/2/106/_pdf $>$. Acesso em: 10 fev. 2012. doi: 10.2141/jpsa.009096.

LEE, K.W. et al. Bacillus subtilis-based direct-fed microbials augment macrophage function in broiler chickens. Research in Veterinary Science, v.91, n.3, p.e87-e91, 2011. Disponível em: $<$ http://www.sciencedirect.com/science/article/pii/S0034528811 000336> . Acesso em: 05 fev. 2012. doi: 10.1016/j.rvsc.2011.01.018.

LI, S.P. et al. Synergy of Astragalus polysaccharides and probiotics (Lactobacillus and Bacillus cereus) on immunity and intestinal microbiota in chicks. Poultry Science, v.88, p.519-525, 2009. Disponível em: <http://ps.fass.org/content/88/3/519.full. pdf + html $>$. Acesso em: 06 fev. 2012. doi:10.3382/os.2008-00365.

LILLY, D.M.; STILLWELL, R.H. Probiotics. Growth promoting factors produced by micro- organisms. Science, v.147, p.747-748, 1965. Disponível em: <http://www.sciencemag. org/content/147/3659/747.short>. Acesso em: 07 fev. 2012. doi:10.1126/science.147.3659.747.

LINDGREN, S.E.; DOBROGOSZ, W.J. Antagonistic activities of lactic acid bacteria in food and feed fermentations. FEMS Microbiology Letters, v.87, n.1-2, p.149-163, 1990. Disponível em: <www.sciencedirect.com/science/article/pii/037810979090703S >. Acesso em: 02 mar. 2012. doi: 10.1111/j.1574-6968.1990.tb04885.x.

MARIANELLI, C. et al. Evaluation of antimicrobial activity of probiotic bacteria against Salmonellaenterica subsp. entericaserovar Typhimurium 1344 in a common medium under different environmental conditions. Research in Microbiology, v.161, p.673-680, 2010. Disponível em: $<$ http://www.sciencedirect. com/science/article/pii/S0923250810001464>. Acesso em 03 mar. 2012. doi: 10.1016/j.resmic.2010.06.007.

MORSE, E.V.; DUNCAN, M.A. Salmonellosis an environmental health problem. Journal of the American Veterinary Medical Association, v.165, p.1015-1019, 1974.

NAZEF, L. et al. Identification of lactic acid bacteria from poultry feces: evidence on Anti-Campylobacter and anti-Listeria activities. Poultry Science, v.87, p.329-334, 2008. Disponível em: <http:// 
ps.oxfordjournals.org/content/87/2/329.full.pdf + html $>$. Acesso em: 10/ fev. 2012. doi: 10.3382/os.2007-00282.

NOUJAIM, J.C et al. Detection of T lymphocytes in intestine of broiler chicks treated with Lactobacillus spp. and challenged with Salmonella enterica Serovar Enteritidis. Poultry Science, v.87, p.927-933, 2008. Disponível em: <http://ps.oxfordjournals.org/ content/87/5/927.full.pdf+html>. Acesso em: 18 fev. 2012.

NOUSIAINEN, J. et al. Lactic acid bacteria as animal probiotics. In: SALMINEN, S. et al. Lactic acid bacteria microbiological and functional aspects. New York: Marcel Dekker, 2005. Cap.20.

OUWEHAND, A.C.; VESTERLUND, S. Antimicrobial components from lactic acid bacteria. In: SALMINEN, S. et al. Lactic acid bacteria microbiological and functional aspects. New York: Marcel Dekker, 2005. Cap.11.

RASSCHAERT, G. et al. Impact of the slaughter line contamination on the presence of Salmonella on broiler carcasses. Journal of Applied Microbiology, v.103, n.2, p.333-341, 2007. Disponível em: <http://onlinelibrary.wiley.com/doi/10.1111/j.1365-2672.20 06.03248.x/pdf $>$. Acesso em: 20 fev. 2012. doi:10.1111/j.13652672.2006.03248.x.

SALMINEN, S. et al. Demonstration of safety of probiotics a review. International Journal of Food Microbiology. v. 44, p.93-106, 1998. Disponível em: <http://www.sciencedirect.com/ science/article/pii/S0168160598001287>. Acesso em 20 fev 2012.

SCHAREK, L. et al. Influence of a probiotic Enterococcus faecium strain on development of the immune system of sows and piglets. Veterinary Immunology and Immunopathology, v.105, p.151-161, 2005. Disponível em: <www.sciencedirect. com/science/article/pii/S0165242705000036>. Acesso em: 20 fev. 2012. doi: 10.1016/j.vetimm.2004.12.022.

TODORIKI, K. et al. Inhibition of adhesion of food-borne pathogens to Caco-2 cells by Lactobacillus strains. Journal of Applied Microbiology, v.91, p.154-159, 2001. Disponível em: $<$ http://onlinelibrary.wiley.com/doi/10.1046/j.1365-2672.2001.01 371.x/pdf>. Acesso em: 21 mar, 2012. doi: 10.1046/j.13652672.2001.01371.x

UNIÃO BRASILEIRA DE AVICULTURA(UBABEF). Relatório anual 2013. Disponível em: $<$ http://www.ubabef.com.br/files/pub licacoes/732e67e684103de4a2117dda9ddd280a.pdf $>$. Acesso em: 04 jan. 2014

VILÀ, B. et al. Reduction of Salmonella enterica var. Enteritidis colonization and invasion by Bacillus cereus var. toyoi inclusion in poultry feeds. Poultry Science, v.88, p.975-979, 2009. Disponível em: <http://ps.oxfordjournals.org/content/88/5/975.full.pdf + html $>$. Acesso em: 13 fev. 2012. doi: 10.3382/os.2008-00483. 